\title{
Fatores que influenciaram na não adoção das recomendações de auditorias: o caso IFRJ
}

Esta pesquisa baseia-se na visão dos gestores da organização pública pesquisada, dos gestores de um órgão de controle federal, dos servidores contemplados com os controles adotados a partir das recomendações de auditoria. Abordando a governança, a governança pública, a accountability/responsabilização e a auditoria. Além de examinar a influência da adoção das recomendações de auditoria emitidas e seus desdobramentos no processo de gestão. A partir dos resultados do estudo foi possível identificar através da análise qualitativa que os fatores que influenciaram a não adoção das recomendações, como sendo, a morosidade, a falta de empenho, muita rotatividade, a ausência de histórico, o tempo, a falta de servidores, a pouca proatividade, a distribuição geográfica, a ausência de uniformidade e o relacionamento interpessoal. Os resultados demonstraram também que a organização pública pesquisada não faz a gestão do conhecimento gerado institucionalmente para disseminar, documentar e compartilhar suas informações.

Palavras-chave: Governança; Auditoria; Gestão Pública; Controle; Accountability.

\section{Factors that influenced the failure to adopt audit recommendations: the IFRJ case}

\begin{abstract}
This research is based on the view of the managers of the researched public organization, of the managers of a federal control body, of the civil servants contemplated with the controls adopted from the audit recommendations. Addressing governance, public governance, accountability/accountability and auditing. In addition to examining the influence of the adoption of the issued audit recommendations and their consequences on the management process. From the results of the study it was possible to identify through the qualitative analysis that the factors that influenced the non-adoption of the recommendations, such as, the delay, the lack of commitment, a lot of turnover, the absence of history, the time, the lack of servers, little proactivity, geographic distribution, lack of uniformity and interpersonal relationships. The results also demonstrated that the researched public organization does not manage the institutionally generated knowledge to disseminate, document and share its information.
\end{abstract}

Keywords: Governance; Audit; Public Management; Control; Accountability.

\section{Topic: Gestão Pública}

Reviewed anonymously in the process of blind peer
Received: 04/06/2020

Approved: 29/07/2020

Danielle Silva de Araujo

Universidade Federal Rural do Rio de Janeiro, Brasil

http://lattes.cnpq.br/6501352097624550

danielle.saraujo100@gmail.com

d

DOI: 10.6008/CBPC2179-684X.2020.003.0015
Referencing this:

ARAUJO, D. S.. Fatores que influenciaram na não adoção das recomendações de auditorias: o caso IFRJ. Revista Brasileira de Administração Científica, v.11, n.3, p.210-227, 2020. DOI: http://doi.org/10.6008/CBPC2179-684X.2020.003.0015 


\section{INTRODUÇÃO}

Na administração pública contemporânea, o serviço público deve levar em consideração o bem-estar social, a equidade, a igualdade de oportunidades e a distribuição justa de "bens públicos" para todos os cidadãos (VIGODA, 2000). Segundo Vigoda (2002), a adoção de um modelo de gestão orientado para o cidadão trabalhou em benefício das burocracias, iluminando dimensões negligenciadas nas relações entre os cidadãos, o Governo e a Administração Pública (G \& AP). Pode-se destacar, dentre outras, a assunção de maior responsabilidade pelo $\mathrm{G} \& \mathrm{AP}$ em relação aos cidadãos; prestação de contas e transparência da operação do setor público; melhorias contínuas no monitoramento das ações dos governos para garantir a eficiência, a eficácia e o melhor desempenho econômico e social; e o reconhecimento de que o poder do governo deve depender, principalmente, do apoio, da voz e da satisfação dos cidadãos em relação aos serviços sob a responsabilidade da administração pública.

No intuito de melhorar a administração pública, o Reino Unido, inovando as práticas existentes, foi um dos pioneiros na implementação da "Nova Administração Pública", que foi formatada do final da década de 1970 até o final da década de 1990. Esse novo modelo foi influenciado por imagens da administração do setor privado, saindo de estruturas de controle tradicionais da sociedade industrial e acatando as demandas de uma sociedade cada vez mais consciente de sua produção de riscos (POWER, 1996).

No contexto da "Nova Administração Pública" onde transparência e accountability se tornaram os valores centrais, as práticas de auditoria destacam-se como uma atividade indispensável para uma avaliação objetiva das organizações públicas, oferecendo conhecimentos sobre a eficácia e a eficiência da gestão. De acordo com a Organização Internacional das Entidades Fiscalizadoras Superiores (INTOSAI, 2015): “A auditoria do setor público pode ser descrita como um processo sistemático de obter e avaliar objetivamente evidências para determinar se a informação ou as condições reais de um objeto estão de acordo com critérios estabelecidos". Ainda, consideram a auditoria do setor público importante, uma vez que oferece informações aos órgãos legislativos e de controle e aos responsáveis pela governança e ao público em geral, na medida que avalia de forma independente e objetiva a gestão, o desempenho de políticas, programas e operações governamentais.

No Brasil, a Controladoria-Geral da União (CGU) tem se destacado como órgão do Governo Federal responsável por realizar atividades relacionadas à defesa do patrimônio público e ao incremento da transparência da gestão, por meio de ações de auditoria pública, correição, prevenção e combate à corrupção e ouvidoria. As características gerais para reconhecimento dos benefícios decorrentes das ações desenvolvidas pela CGU são variadas e foram classificadas através da Portaria no 1.276, de 05 de junho de 2017 da CGU como benefício, benefício financeiro, benefício não financeiro e prejuízo, no quadro abaixo.

No âmbito do Instituto Federal de Educação, Ciência e Tecnologia do Rio de Janeiro (IFRJ), que é a organização escolhida para realização do presente estudo, a CGU foi responsável pela realização de 17 (dezessete) ações de auditoria, entre os anos de 2012 e 2017. Essas ações de auditoria resultaram em um conjunto de recomendações. Contudo, até maio de 2019 , apenas $52,7 \%$ do total das recomendações 
emitidas pela CGU ao IFRJ foram atendidas.

Quadro 1: Características gerais para reconhecimento dos benefícios decorrentes das ações executadas pela CGU.

\begin{tabular}{|l|l|}
\hline $\begin{array}{c}\text { Características } \\
\text { gerais }\end{array}$ & \multicolumn{1}{c|}{ Descrição das características gerais } \\
\hline Benefício & $\begin{array}{l}\text { Impactos positivos observados na gestão pública a partir da implementação, por parte dos gestores } \\
\text { públicos, de orientações e/ou recomendações provenientes das ações executadas pela CGU }\end{array}$ \\
\hline $\begin{array}{l}\text { Benefício } \\
\text { financeiro }\end{array}$ & $\begin{array}{l}\text { Benefício que possa ser representado monetariamente e demonstrado por documentos comprobatórios, } \\
\text { preferencialmente fornecidos pelo gestor, inclusive decorrentes de recuperação de prejuízos }\end{array}$ \\
\hline $\begin{array}{l}\text { Benefício não } \\
\text { financeiro }\end{array}$ & $\begin{array}{l}\text { Benefício que, embora não seja passível de representação monetária, demonstre um impacto positivo na } \\
\text { gestão de forma estruturante, tal como melhoria gerencial, melhoria nos controles internos e } \\
\text { aprimoramento de normativos e processos, devendo sempre que possível ser quantificado em alguma } \\
\text { unidade que não a monetária }\end{array}$ \\
\hline Prejuízo & Danos ao erário que resulte em recomendação de reposição de bens e valores \\
\hline
\end{tabular}

Fonte: Portaria no 1.276, de 05 de junho de 2017 da CGU que Institui conceitos e orientações relacionados aos benefícios financeiros e não financeiros, e revoga a Portaria no 2.379, de 30 de outubro de 2012.

O tempo padrão de atendimento dessas recomendações é de 2,7 anos, o que corresponde aproximadamente a 990 dias. A variabilidade é de 53,77\%, o que significa que o número de dias até o atendimento das recomendações não segue um padrão homogêneo. O maior período até o atendimento foi de 5,78 anos, e existem recomendações que obtiveram atendimento em torno deste período máximo, o que corresponde a aproximadamente 2.135 dias.

A informação supracitada chama atenção, pois o intervalo para o atendimento às recomendações foi moroso, perpassando o período de realização de 2 (duas) auditorias anuais de contas pela CGU e 2 (dois) julgamentos de contas pelo Tribunal de Contas da União (TCU). Essa morosidade pode ensejar ressalvas no certificado de auditoria emitido pela CGU, bem como ser motivo de reprovação das contas, ou de aprovação com ressalvas pelo TCU, conforme pode ser observado no Acórdão no 2611/2019 - TCU - 2a Câmara emitido ao IFRJ que manifestou-se sobre a ausência de controle prévio para identificação e tratamento de indícios de irregularidades detectados pela CGU desde 2013, e julgou regulares com ressalva suas contas, não houve dano ou prejuízo ao Erário Público, contudo existem fragilidades que devem ser tratadas.

Com base nesse Acórdão, fica evidente a importância do papel desempenhado pelas atividades de auditoria no setor público, bem como a relevância dos estudos que investiguem o funcionamento dessas atividades e as suas contribuições para a melhoria dos controles internos das organizações públicas. Diante do que foi exposto, o questionamento que norteou esta investigação foi: Quais os fatores que influenciaram na adoção das recomendações da auditoria externa?.

Além desta introdução, o presente artigo está organizado da seguinte maneira: A segunda seção trata de revisão da literatura sobre governança, governança pública, accountability e auditoria. Na terceira seção, metodológica, é apresentada a fonte da base de dados recorrida, além das análises de dados aplicadas. Na quarta seção são apresentados os resultados e as discussões sobre esses resultados, isto é, fatores identificados que colaboram para a adoção dos controles em atendimento às recomendações de auditoria emitidas pela CGU e seus desdobramentos. Por fim, há uma seção de considerações finais.

\section{REVISÃO TEÓRICA}

\section{Governança, governança pública, accountability/responsabilização e auditoria}




\section{Governança}

No momento em que as organizações deixaram de ser administradas por seus proprietários surgiu então a governança, uma vez que esses proprietários passaram a administração de seu capital para terceiros, a quem foi dada a autoridade e o poder para gerir esses recursos. Com essa delegação de autoridade podem surgir divergências de interesses entre proprietários e administradores. Esse problema tende a se acentuar em um contexto de assimetria da informação, tendo em vista que os administradores podem buscar maximizar seus objetivos individuais em detrimento dos objetivos dos proprietários da organização, que no âmbito dos serviços públicos é a população de um país, estado ou munícipio, de acordo com o Referencial Básico de Governança do TCU emitido em 2014.

Assim como a Nova Gestão Pública - NGP, a governança tem interesse nos resultados produzidos pelas organizações e considera os controles de entrada, que são os mecanismos de controle preferidos na administração pública tradicional, insuficientes (PETERS et al., 1998). De acordo com o autor supracitado, a insuficiência do controle tradicional ocorre porque ele esconde lacunas, não é eficiente organizacionalmente, não relaciona desempenho com a demanda e a satisfação do cliente. Entende-se que o controle de saída, defendido tanto pela NGP quanto pela governança, se manifesta através da satisfação do cliente, de indicadores de desempenho e da geração de conformidade. Uma vez que a governança mistura valores públicos e privados, a NGP pode ser descrita como o ingresso de valores e objetivos da esfera corporativa no setor público e na entrega de serviços públicos (PETERS et al., 1998).

\section{Governança Pública}

Assim como todos os modelos de serviço público, a governança é derivada da cultura política dentro da qual está incorporada. O surgimento da governança, portanto, aparece em diferentes formas institucionais e em diferentes contextos nacionais (PETERS et al., 1998). Para que as funções de governança (avaliar, direcionar e monitorar) sejam realizadas de forma efetiva, alguns mecanismos devem ser perseguidos: a liderança, a estratégia e o controle de acordo com o Referencial Básico de Governança do TCU emitido em 2014, no quadro a seguir.

Quadro 2: Definição dos mecanismos de governança.

\begin{tabular}{|l|l|}
\hline Mecanismo & Definição \\
\hline Liderança & $\begin{array}{l}\text { Liderança refere-se ao conjunto de práticas, de natureza humana ou comportamental, que assegura a existência } \\
\text { das condições mínimas para o exercício da boa governança, quais sejam: pessoas íntegras, capacitadas, } \\
\text { competentes, responsáveis e motivadas ocupando os principais cargos das organizações e liderando os processos } \\
\text { de trabalho. }\end{array}$ \\
\hline Estratégia & $\begin{array}{l}\text { Esses líderes são responsáveis por conduzir o processo de estabelecimento da estratégia necessária à boa } \\
\text { governança, envolvendo aspectos como: escuta ativa de demandas, necessidades e expectativas das partes } \\
\text { interessadas; avaliação do ambiente interno e externo da organização; avaliação e prospeç̧ão de cenários; } \\
\text { definição e alcance da estratégia; definição e monitoramento de objetivos de curto, médio e longo prazos; } \\
\text { alinhamento de estratégias e operações das unidades de negócio e organizações envolvidas ou afetadas. }\end{array}$ \\
\hline Controle & $\begin{array}{l}\text { Entretanto, para que esses processos sejam executados, existem riscos, os quais devem ser avaliados e tratados. } \\
\text { Para isso, é conveniente o estabelecimento de controles e sua avaliação, transparência e accountability, que } \\
\text { envolve, entre outras coisas, a prestação de contas das ações e a responsabilização pelos atos praticados. }\end{array}$ \\
\hline
\end{tabular}

Fonte: Referencial Básico de Governança do TCU emitido em 2014.

Pereira (2010) explica que: 
A governança nas organizações públicas e privadas apresenta significativas similitudes. Levando-se em consideração que o setor público e o privado possuem focos específicos, observa-se que são comuns entre eles as questões que envolvem a separação entre propriedade e gestão, responsável pela geração dos problemas de agência, os instrumentos definidores de responsabilidades e poder, o acompanhamento e o incentivo na execução das políticas e objetivos definidos, entre outros. Verifica-se, em um sentido amplo, que os princípios básicos que norteiam os rumos dos segmentos dos setores privado e público são idênticos: transparência, equidade, cumprimento das leis, prestação de contas e conduta ética.

O sistema de governança remete à forma como os diversos atores se organizam, interagem e trabalham para obter a boa governança. Aborda as estruturas administrativas (instâncias), os processos de trabalho, os instrumentos (ferramentas, documentos, etc.), o fluxo de informações e o comportamento de pessoas envolvidas, direta ou indiretamente, na avaliação, no direcionamento e no monitoramento da organização, como mencionado no Referencial Básico de Governança do TCU emitido em 2014. De acordo com informações oficiais da Política de governança da administração pública federal direta, autárquica e fundacional, (BRASIL, 2017), são princípios da governança pública: capacidade de resposta, integridade, confiabilidade, melhoria regulatória, prestação de contas, responsabilidade e transparência.

\section{Accountability/Responsabilização}

A responsabilização pública é a marca de governos democráticos. Se os que estão no poder não forem responsabilizados por seus atos e omissões, a democracia continuará sendo um procedimento em papel, não obstante a accountability pública, como instituição, seja o complemento da gestão pública, conceitualmente definida como "responsabilidade pública" (BOVENS, 2005).

Cabe destacar que Bovens (2005): "accountability não se refere a soberanos que mantêm seus súditos sob controle, mas ao contrário, são as próprias autoridades que estão sendo responsabilizadas por seus cidadãos". Ele esclarece que o conceito de accountability é uma relação entre um ator e um fórum, na qual o ator tem a obrigação de explicar e justificar sua conduta, o fórum pode colocar questões e julgar, e o ator pode enfrentar consequências.

A ideia contida na palavra accountability traz subentendida a responsabilização pessoal pelos atos praticados, e é bem esclarecido o dever de realizar a prestação de contas, seja no âmbito público ou no privado (PINHO et al., 2009). Existe a necessidade de redirecionar a atividade governamental, aglutinando no setor público qualidade com eficiência, flexibilidade organizacional com accountability e criatividade com busca de equidade (ABRUCIO, 1997).

Destaca-se que Instrução Normativa Conjunta MP/CGU no 01, de 10 de maio de 2016 descreve a accountability como sendo conjunto de procedimentos utilizados nas organizações públicas pelos indivíduos que as compõem e que demonstram responsabilidade pelas decisões tomadas e ações implementadas, tais como a salvaguarda de recursos públicos, a imparcialidade e o desempenho organizacional, assim como a obrigação de assumir responsabilidades pelas decisões e pela prestação de contas da atuação realizada, assumindo as consequências de seus atos e omissões.

A Controladoria destaca também que a accountability é um dos princípios da boa governança, 
devendo ser seguido pelos órgãos e entidades do Poder Executivo Federal. Osborne (2010) esclarece que a accountabilityé, muitas vezes, conceituada como um mecanismo para reforçar o controle sobre organizações e programas públicos, mas também é um meio de orientar a melhoria dos programas. Bovens (2005) destaca que a accountability foi além de suas origens contábeis e se tornou um símbolo da boa governança, tanto no setor público quanto no privado.

Já para Osborne (2010) a principal questão que surge no desenvolvimento do NGP e dos estilos de governança no setor público é a responsabilidade pelas decisões que são tomadas em nome do público. Neste ponto cabe mencionar que a Constituição da República Federativa do Brasil (1988), no seu Art. 70, $\S$ único) discorre que "[...] prestará contas qualquer pessoa física ou jurídica, pública ou privada, que utilize, arrecade, guarde, gerencie ou administre dinheiros, bens e valores públicos ou pelos quais a União responda, ou que, em nome desta, assuma obrigações de natureza pecuniária".

\section{Auditoria}

A auditoria é um conjunto de valores, tais como validação independente, eficiência, racionalidade, visibilidade de forma parcialmente independente da disciplina prática e promessa de controle, e todas essas aparentes virtudes demonstram que a auditoria é uma parte central da "reinvenção do governo" (POWER, 1996). De acordo com a Instrução normativa no 01, de 06 de abril de 2001, que define diretrizes, princípios, conceitos e aprova normas técnicas para a atuação do Sistema de Controle Interno do Poder Executivo Federal (BRASIL, 2001):

A auditoria é o conjunto de técnicas que visa avaliar a gestão pública, pelos processos e resultados gerenciais, e a aplicação de recursos públicos por entidades de direito público e privado, mediante a confrontação entre uma situação encontrada com um determinado critério técnico, operacional ou legal. Trata-se de uma importante técnica de controle do Estado na busca da melhor alocação de seus recursos, não só atuando para corrigir os desperdícios, a improbidade, a negligência e a omissão e, principalmente, antecipando-se a essas ocorrências, buscando garantir os resultados pretendidos, além de destacar os impactos e benefícios sociais advindos.

A execução do trabalho desenvolvido em uma auditoria se dá por meio da coleta de dados, os quais, após serem avaliados, evidenciam as situações encontradas, o que fomenta as questões da auditoria. Neste caso é concedida pelo auditor à unidade auditada a oportunidade de se manifestar sobre o assunto em questão. Depois disso, o resultado de todo o trabalho é comunicado aos envolvidos e são emitidas recomendações, a fim de que sejam sanadas as impropriedades detectadas. Até que haja resolução, essas recomendações são monitoradas pelos órgãos de controle, figura abaixo.

De acordo com as Normas brasileiras de auditoria do setor público - NBASP (IRB, 2017), nível dois: princípios fundamentais de auditoria do setor público, as auditorias do setor público partem de objetivos que podem ser distintos, dependendo do tipo de auditoria que está sendo realizada; no entanto, todas elas contribuem para a boa governança, pois "fornecem aos usuários previstos, com independência, informações objetivas e confiáveis, conclusões ou opiniões baseadas em evidência suficiente e apropriada, relativas às entidades públicas" (IBR, 2017). Aperfeiçoa também a accountability e a transparência, proporcionando melhorias no uso dos recursos públicos e no desempenho da administração pública, além de fortalecer a 
efetividade dos órgãos públicos.

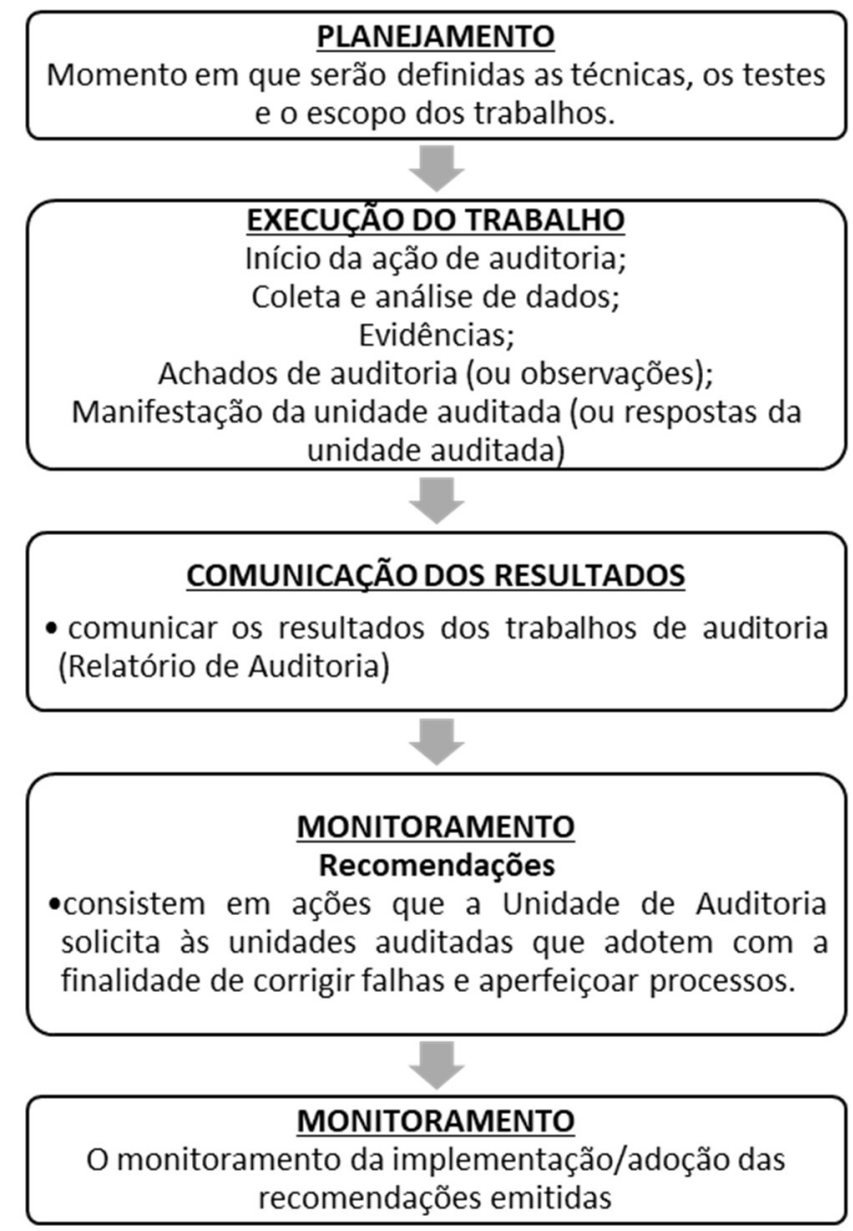

Figura 1: O processo de execução do trabalho de avaliação

Fonte: Manual de orientações técnicas da atividade de auditoria interna governamental do Poder Executivo Federal, CGU et al. (2017).

\section{METODOLOGIA}

O propósito desta pesquisa aplicada foi identificar os fatores que influenciam na adoção das recomendações de auditoria emitidas por um órgão de controle em uma organização pública, a partir dos relatórios de auditoria emitidos pela CGU e suas recomendações. Para Vergara (1990), pesquisa de natureza aplicada é um "estudo sistemático fundamentalmente motivado pela necessidade de resolver problemas concretos, mais imediatos, ou não".

A investigação assumiu a característica de estudo de caso. De acordo com Yin (2005), "um estudo de caso é uma investigação empírica que investiga um fenômeno contemporâneo dentro de seu contexto da vida real, especialmente quando os limites entre o fenômeno e o contexto não estão claramente definidos". No intuito de alcançar os objetivos propostos, este estudo é considerado, conforme Creswell (2014), como pesquisa qualitativa, pois buscou identificar a percepção dos sujeitos envolvidos com o fenômeno investigado.

Foi realizada uma pesquisa quantitativa, cujo método quantitativo caracteriza-se pelo emprego de dados quantitativos, obtidos pela coleta de dados e pelo tratamento destes por meio de técnicas estatísticas. Amplamente utilizado na condução de pesquisas, o método quantitativo procura descobrir e classificar a 
relação entre as variáveis.

Para coleta de dados foram utilizadas duas estratégias. A primeira foi a aplicação de questionários aos servidores envolvidos/influenciados pela recomendação de auditoria implementada, quadro seguinte. A segunda foi a realização de entrevistas semiestruturadas com os gestores dos setores que atenderam ou estão por atender às recomendações da auditoria externa, gestores da CGU, considerando 3 (três) grupos diferentes de agentes, nos quadros: Lista dos gestores do IFRJ entrevistados nesta pesquisa; e Códigos dos gestores do IFRJ entrevistados por situação de atendimento as recomendações.

O formulário de pesquisa referente aos controles internos implementados no IFRJ para 54 (cinquenta e quatro) servidores foi enviado, por e-mail. A amostra foi selecionada a partir dos documentos institucionais elaborados para atender às recomendações de auditoria emitidas pela CGU (elaboração de documentos, realização de manuais, portarias, aprimoramento de processos e documentos que contemplassem mais de 4 (quatro) pessoas alcançadas com sua implementação após seu atendimento, no quadro a seguir. Esse formulário não poderia ser respondido mais de uma vez pelo servidor. O questionário ficou aberto para preenchimento de 28/03/2019 a 24/04/2019. A taxa de resposta ficou em $38,9 \%$.

Quadro 3: Amostra composta por 6 (seis) recomendações atendidas sobre as quais os sujeitos contemplados com suas implementações responderam ao questionário

\begin{tabular}{|c|c|c|}
\hline Recomendação & Documento & Recomendação \\
\hline 137238 & $\begin{array}{l}\text { Instrução de Serviço } 07.2016 \text { - Atesto de bens, } \\
\text { serviços e materiais }\end{array}$ & $\begin{array}{l}\text { Estabelecer procedimentos internos que definam as } \\
\text { competências e obrigações das áreas envolvidas nas } \\
\text { etapas de [...], incluindo relatórios e demonstrativos } \\
\text { previstos. }\end{array}$ \\
\hline 127502 & Manual de Patrimônio & $\begin{array}{l}\text { Implementar sistemática integrada para registro e } \\
\text { controle de patrimônio no âmbito do IFRJ. }\end{array}$ \\
\hline 127495 & $\begin{array}{l}\text { Regimento interno do Comitê de Compras, } \\
\text { Licitações e Contratos do IFRJ; Portaria 112-2015 - } \\
\text { Comitê de Compras do IFRJ }\end{array}$ & $\begin{array}{l}\text { Realizar o planejamento nas aquisições de compras a } \\
\text { partir do levantamento das especificações dos } \\
\text { materiais e de seus quantitativos baseados nas } \\
\text { demandas dos setores requisitantes, anexando tais } \\
\text { documentos aos próximos processos de compras. }\end{array}$ \\
\hline 58596 & $\begin{array}{l}\text { Resolução CONSUP no 43, de } 20 \text { de outubro de } \\
\text { 2017, aprovando o Regimento Interno da } \\
\text { Auditoria Interna da unidade. Resolução CONSUP } \\
\text { no 44, de } 20 \text { de outubro de } 2017 \text {, aprovando o } \\
\text { Manual da Auditoria Interna (Audin). }\end{array}$ & $\begin{array}{l}\text { Normatize, em caráter complementar à normatização } \\
\text { da CGU, a atividade de auditoria interna, }[\ldots] .\end{array}$ \\
\hline 81546 & $\begin{array}{l}\text { Resolução CONSUP } \mathrm{n} \text { - 43, de } 20 \text { de outubro de } \\
\text { 2017, aprovando o Regimento Interno da } \\
\text { Auditoria Interna da unidade. Resolução CONSUP } \\
\text { no 44, de } 20 \text { de outubro de } 2017 \text {, aprovando o } \\
\text { Manual da Auditoria Interna (Audin). }\end{array}$ & $\begin{array}{l}\text { Elaborar e arquivar junto aos papéis de trabalho } \\
\text { documentação referente ao planejamento de cada } \\
\text { ação de auditoria realizada, detalhando o que for } \\
\text { necessário à compreensão dos procedimentos que } \\
\text { serão aplicados, em termos de natureza, oportunidade } \\
\text { e extensão. }\end{array}$ \\
\hline 57820 & $\begin{array}{l}\text { Foi realizado o Curso in Company Avançado sobre } \\
\text { licitações e contratos públicos, cujo conteúdo } \\
\text { programático apresentado na proposta comercial } \\
\text { da empresa responsável pelo treinamento abrange } \\
\text { pregão eletrônico e sistema de registro de preços. } \\
\text { Foi apresentada também a lista de presença dos } \\
\text { participantes do curso }\end{array}$ & $\begin{array}{l}\text { Realizar ações de capacitação do quadro de pessoal } \\
\text { voltadas para a contratação por pregão eletrônico no } \\
\text { sistema de registro de preços. }\end{array}$ \\
\hline
\end{tabular}

Fonte: recomendações retiradas do Sistema Monitor ${ }^{1}$ da CGU.

Para as entrevistas com os gestores do IFRJ realizou-se a seleção das recomendações de auditoria,

\footnotetext{
${ }^{1}$ O Monitor é o sistema desenvolvido pela Controladoria-Geral da União (CGU) que permite o acompanhamento online das recomendações realizadas no âmbito do controle interno do Poder Executivo Federal, por meio das ações de auditoria e fiscalização.
} 
atendidas e não atendidas, e a identificação dos gestores responsáveis por seu atendimento, ou pela pretensão de seu atendimento, visto que o tempo de atendimento das recomendações varia em torno dos 3 anos. Depois que este levantamento foi realizado, as entrevistas foram iniciadas com a apresentação dessas recomendações aos entrevistados, a fim de que pudessem relembrar os temas tratados. As entrevistas com os 10 (dez) gestores do IFRJ (códigos de E1 ao E10), quadro seguinte, e os códigos dos atendimentos e não atendimentos, quadro Códigos dos gestores do IFRJ entrevistados por situação de atendimento as recomendações, foram realizadas nas dependências do Instituto, nos campi e sedes da reitoria, entre os dias 15/04/2019 e 30/04/2019.

Quadro 4: Lista dos gestores do IFRJ entrevistados nesta pesquisa.

\begin{tabular}{|l|l|l|l|l|l|l|}
\hline Seq. & Código & Formação & Idade & $\begin{array}{l}\text { Tempo como } \\
\text { gestor (anos) }\end{array}$ & $\begin{array}{l}\text { Tempo no IFRJ } \\
\text { (anos) }\end{array}$ & $\begin{array}{l}\text { Código } \\
\text { cargo }^{2} / \text { função }^{3}\end{array}$ \\
\hline 1 & E1 & Tecnólogo em Recursos Humanos & 52 & 2,0 & 25 & CD4 \\
\hline 2 & E2 & Bacharelando em Administração & 31 & 0,2 & 7 & CD4 \\
\hline 3 & E3 & Bacharel em Direito & 24 & 1,8 & 3 & FG1 \\
\hline 4 & E4 & Bacharel em Contabilidade & 36 & 0,8 & 10 & CD4 \\
\hline 5 & E5 & Administrador & 29 & 1,0 & 3 & CD4 \\
\hline 6 & E7 & Especialista em Gestão Pública & 41 & 2,2 & 12 & CD4 \\
\hline 7 & E6 & Mestre em Sistemas e Computação & 59 & 4,0 & 25 & CD2 \\
\hline 8 & E8 & Tecnólogo em Gestão Pública & 28 & - & 3 & - \\
\hline 9 & E9 & Engenheiro & 61 & 8,5 & 33 & CD4 \\
\hline 10 & E10 & Administrador & 36 & 3,5 & 9 & CD3 \\
\hline
\end{tabular}

Fonte: Elaborado pela autora a partir das entrevistas com os gestores.

Quadro 5: Códigos dos gestores do IFRJ entrevistados por situação de atendimento as recomendações

\begin{tabular}{|c|c|c|c|c|}
\hline \multirow[t]{2}{*}{ Seq. dos entrevistados } & \multicolumn{2}{|c|}{ Agente com Recomendação } & \multicolumn{2}{|c|}{ Código dos entrevistados } \\
\hline & Atendida & Não atendida & Atendida & Não atendida \\
\hline E1 & $\mathrm{X}$ & $\mathrm{X}$ & E1A & E1NA \\
\hline E2 & & $\mathrm{x}$ & & E2NA \\
\hline E3 & $\mathrm{x}$ & $\mathrm{x}$ & E3A & E3NA \\
\hline E4 & & $x$ & & E4NA \\
\hline E5 & & $x$ & & E5NA \\
\hline E6 & $x$ & $\mathrm{x}$ & E6A & E6NA \\
\hline E7 & & $x$ & & E7NA \\
\hline E8 & $x$ & $\mathrm{x}$ & E8A & E8NA \\
\hline E9 & $x$ & & E9A & \\
\hline E10 & $\mathrm{x}$ & & E10A & \\
\hline
\end{tabular}

Com o objetivo de analisar os desdobramentos das atividades de auditoria sobre o processo de gestão do IFRJ, bem como verificar se as proposições de melhorias para as organizações públicas oriundas da CGU estão sendo alcançadas pelo Instituto, foram realizadas 3 (três) entrevistas com gestores que atuaram na CGU entre os anos de 2012 e 2017, período em que as recomendações foram emitidas, conforme quadro seguinte. Essas entrevistas ocorreram entre os dias 29/03/2019 e 22/05/2019.

Quadro 6: Gestores que atuaram na CGU dentro do período de emissão das recomendações (2012 a 2017) com os códigos utilizados para a identificação.

\begin{tabular}{|l|l|l|l|}
\hline Seq. & Código dos entrevistados & Nível & Tempo de CGU (anos) \\
\hline $\mathbf{1}$ & G1 & Estratégico & 14 \\
\hline $\mathbf{2}$ & G2 & Tático & 23 \\
\hline $\mathbf{3}$ & G3 & Operacional & 18 \\
\hline
\end{tabular}

Fonte: Elaborado a partir das entrevistas com os gestores da CGU.

${ }^{2}$ Cargos de direção das instituições federais de ensino - CD

${ }^{3}$ Funções gratificadas das instituições federais de ensino - FG 
Esta coleta visou identificar a adoção de controles internos e suas abordagens para o atendimento das recomendações de auditoria procedentes dos relatórios emitidos pela CGU para o IFRJ, de 2012 a 2017.

Para além dos dados primários, coletados por meio de entrevistas e questionários, a pesquisa também envolveu a coleta de dados disponíveis nos documentos institucionais: relatórios de auditoria, relatórios de auditoria emitidos pela CGU ao IFRJ, relatórios retirados do Sistema Monitor da CGU, Planejamento Estratégico IFRJ 2018-2021, Regimento Interno do Comitê de Governança Corporativa e de TI, Riscos e Controles do IFRJ, Relatório de Gestão do IFRJ para o ano de 2017, Relatório de Gestão do IFRJ para o ano de 2016, Regimento Geral do IFRJ, Estatuto do IFRJ. Vale registrar que a pesquisa documental é uma das fontes utilizadas com mais frequência em pesquisas na área de Administração, principalmente como fonte complementar de informações obtidas por meio de entrevistas e questionários (ROESCH, 1999).

\section{RESULTADOS}

As discussões dos resultados foram organizadas por categoria analítica. Analisou-se os fatores que influenciaram a adoção das recomendações de auditoria emitidas pela CGU na visão dos gestores do IFRJ, bem como dos servidores que foram alcançadas pelas recomendações e dos gestores da CGU, buscando identificar os fatores influenciadores.

\section{Fatores que influenciaram na ADOÇÃO das recomendações}

Em relação aos fatores internos ou externos que influenciaram a adoção da recomendação, pode-se observar as seguintes falas dos gestores do IFRJ que atenderam a alguma recomendação de auditoria:

E3A: "Eu acho que com a prática mesmo a gente foi conseguindo atender de acordo com a prática, no início era muito difícil de olhar, mas agora tipo com o tempo vai ficando mais fácil, parece que eu estou mais acostumada [...] Flui melhor. Fica até mais segura, do que eu estou fazendo, antigamente quando eu não estava segura eu ficava: 'se eu fizer besteira?!".

E6A: "Eu acho que a gente tem que dedicar um tempo do trabalho para isso, eu acho que o mais importante é isso, mas a gente começou a parte da criação da governança, tem que criar uma estrutura interna para viabilizar, mas não é fácil você escrever, implementar, botar as coisas para fazer, mas eu acho que a governança e o pessoal que chegou aquele aumento dos servidores contribuiu muito".

E9A: "Internamente sempre a partir, da direção, quando toma conhecimento das recomendações dos órgãos de controle, nós temos que atender e a direção nos dá subsídio também para isso, por que não adianta o órgão de controle recomenda e a direção nos dá subsídio para atender não teremos como atender. [...]".

Os fatores que influenciaram a adoção da recomendação de auditoria foram para os gestores que atenderam a alguma recomendação de auditoria relatado no quadro abaixo.

Quadro 7: Fatores internos ou externos que influenciaram a adoção da recomendação, de acordo com a percepção dos gestores que atenderam a alguma recomendação

\begin{tabular}{|c|c|c|c|}
\hline $\begin{array}{l}\text { Fator } \\
\text { identificado }\end{array}$ & Entrevistado & Fala do gestor & $\begin{array}{lll}\text { Descrição do fator } \\
\text { identificado }\end{array}$ \\
\hline $\begin{array}{l}\text { Experiência/ } \\
\text { prática }\end{array}$ & E3A & $\begin{array}{l}\text { "[...] com a prática mesmo a gente foi conseguindo atender } \\
\text { de acordo com a prática, no início era muito difícil }[. . .] "\end{array}$ & $\begin{array}{l}\text { A experiência no setor } \\
\text { contribuiu para a adoção }\end{array}$ \\
\hline $\begin{array}{l}\text { Dedicação/ } \\
\text { vontade }\end{array}$ & E6A & $\begin{array}{l}\text { "[...] a gente tem que dedicar um tempo do trabalho para } \\
\text { isso [...]" }\end{array}$ & $\begin{array}{l}\text { A dedicação do gestor à } \\
\text { recomendação emitida }\end{array}$ \\
\hline
\end{tabular}




\begin{tabular}{|l|l|l|l|}
\hline gestor & & & \\
\hline Assistência & E9A & $\begin{array}{l}\text { "[...] nós temos que atender e a direção nos dá subsídio } \\
\text { também para isso, por que não adianta o órgão de controle } \\
\text { recomenda e a direção nos dá subsídio para atender não } \\
\text { teremos como atender. [...]" }\end{array}$ & $\begin{array}{l}\text { Assistência por parte da alta } \\
\text { administração } \\
\text { atendimento à recomendação }\end{array}$ \\
\hline $\begin{array}{l}\text { Núcleo } \\
\text { governança }\end{array}$ & "de & $\begin{array}{l}\text { "[..] mas a gente começou a parte da criação da } \\
\text { governança [...]" }\end{array}$ & $\begin{array}{l}\text { A criação do setor: Núcleo de } \\
\text { governança }\end{array}$ \\
\hline Servidores & E6A & $\begin{array}{l}\text { "[...] mas eu acho que a governança e o pessoal que chegou } \\
\text { aquele aumento dos servidores contribuiu muito." }\end{array}$ & $\begin{array}{l}\text { Aumento do número de } \\
\text { servidores após o concurso } \\
\text { realizado em 2015 }\end{array}$ \\
\hline
\end{tabular}

A Figura abaixo apresenta os fatores internos ou externos que influenciaram a adoção da recomendação, na visão dos gestores que atenderam à recomendação. Os fatores foram relacionados a partir da resposta à pergunta: Qual(is) foi(foram) o(s) fator(es) interno(s) ou externo(s) que influenciaram a adoção da recomendação?.

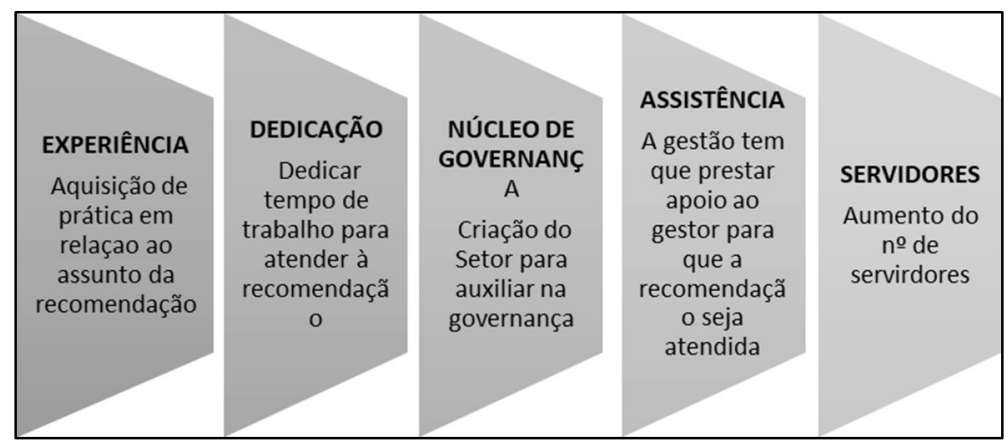

Figura 2: Fatores internos ou externos que influenciaram a adoção da recomendação.

Para os gestores que atenderam a alguma recomendação de auditoria, os fatores que influenciaram a adoção da recomendação de auditoria foram: (i) a experiência no setor; (ii) a dedicação do gestor à recomendação emitida; (iii) a assistência por parte da alta administração; (iv) a criação do núcleo de governança; (v) o aumento do número de servidores após o concurso realizado em 2015. O Quadro seguinte apresenta os fatores que influenciaram a adoção das recomendações, de acordo com a percepção dos servidores que foram atingidos com as recomendações de auditoria.

Quadro 8: Fatores que influenciaram a adoção da recomendação, de acordo com a percepção dos servidores atingidos com os controles implementados ou com as ações tomadas

\begin{tabular}{|c|c|c|}
\hline Fatores ${ }^{4}$ & Qtde. & perc. \\
\hline Planejamento das atividades objeto da auditoria para a melhoria do processo auditado & 11 & $52,4 \%$ \\
\hline Colaboração dos servidores do setor na mudança de cultura anteriormente seguida & 11 & $52,4 \%$ \\
\hline Reflexão por parte do gestor quanto à importância da implementação da recomendação & 9 & $42,9 \%$ \\
\hline Capacitação realizada sobre o assunto objeto da constatação & 5 & $23,8 \%$ \\
\hline Reunião conjunta com os órgãos de controle (CGU) para soluções conjuntas dos problemas apontados & 4 & $19,0 \%$ \\
\hline Feedbacks constantes relacionados às ações enviadas pelo gestor para atendimento das recomendações & 4 & $19,0 \%$ \\
\hline Aumento da quantidade de servidores lotados no setor em relação aos que havia na época da constatação & 3 & $14,3 \%$ \\
\hline Prática administrativa irregular que originou auditoria do objeto & 1 & $4,8 \%$ \\
\hline Não sei opinar & 1 & $4,8 \%$ \\
\hline Não fui informado das recomendações da CGU & 1 & $4,8 \%$ \\
\hline
\end{tabular}

Observa-se que os fatores mais citados foram: planejamento das atividades objeto da auditoria para a melhoria do processo auditado, colaboração dos servidores do setor na mudança de cultura anteriormente

\footnotetext{
${ }^{4}$ Total de respondentes para esta questão: 19 
seguida e reflexão por parte do gestor quanto à importância da implementação da recomendação. De igual modo, quando perguntado aos entrevistados G1, G2 e G3 sobre o que mais contribui, na opinião deles, para o atendimento de uma recomendação, as respostas obtidas foram as seguintes:

G1: "As recomendações serão mais eficazes e efetivas se forem de fato pactuadas e construídas de forma conjunta com os auditados. Esse rito é cumprido pela CGU por meio das reuniões de busca conjunta de soluções, oportunidade em que cada recomendação é discutida e apropriada pelos gestores, que tornam, portanto, suas as recomendações construídas conjuntamente".

G2: “Em poucas palavras, duas questões são fundamentais no processo de recomendação, um bom planejamento e a eficiência na busca conjunta das soluções para os problemas eventualmente encontrados. Outros aspectos também podem influir, porém, se estas duas etapas não forem bem realizadas, o trabalho fica comprometido. A respeito da primeira o planejamento - muito já foi escrito e há normas que precisam ser seguidas, assim seria ocioso abordar. Mas a segunda - o processo de elaboração das recomendações - merece uma abordagem mais detalhada. Na minha opinião, as recomendações precisam ser negociadas, desde que os dois lados estejam cientes e respeitem os princípios basilares da Administração Pública. Posto isto, a negociação deve fluir baseada em uma relação de confiança entre auditores e auditados, todos imbuídos do espírito público e voltados para solucionar as questões que estão impactando a eficiência e eficácia das políticas públicas na sociedade".

G3: "Eu acho que são duas coisas que eu acho que contribui, primeiro a vontade do gestor, assim, se o gestor não tiver interesse em atender a gente não consegue efetivar as recomendações, e a outra questão é a auditoria saber expor o problema, mostrar para o gestor que aquilo é importante, que quando você consegue demonstrar que a questão é importante, que está prejudicando a unidade, que tem um impacto na gestão, eu acho que o gestor toma uma certa consciência que ele precisa fazer alguma coisa, por isso que eu acho que tem esses dois vieses que tem que ser atacados".

O quadro abaixo apresenta os fatores identificados para o atendimento de uma recomendação segundo a visão dos gestores da CGU.

Quadro 9: Fatores identificados para o atendimento de uma recomendação segundo a visão dos gestores da CGU

\begin{tabular}{|c|c|c|c|}
\hline Fator identificado & Entrevistado & Fala do gestor & $\begin{array}{lll}\begin{array}{l}\text { Descrição do fator } \\
\text { identificado }\end{array} & \\
\end{array}$ \\
\hline $\begin{array}{l}\text { Recomendações } \\
\text { construídas } \\
\text { conjuntamente }\end{array}$ & G1 & $\begin{array}{l}\text { [...] As recomendações serão mais eficazes e efetivas se } \\
\text { forem de fato pactuadas e construídas de forma conjunta } \\
\text { com os auditados [...] }\end{array}$ & $\begin{array}{l}\text { Recomendações } \\
\text { construídas } \\
\text { conjuntamente }\end{array}$ \\
\hline Confiança & $\mathrm{G} 2$ & [...] Relação de confiança entre auditores e auditados [...] & $\begin{array}{l}\text { Relação de confiança } \\
\text { entre auditores e } \\
\text { auditados }\end{array}$ \\
\hline Negociação & $\mathrm{G} 2$ & $\begin{array}{l}{[\ldots] \text { Na minha opinião, as recomendações precisam ser }} \\
\text { negociadas, desde que os dois lados estejam cientes e } \\
\text { respeitem os princípios basilares da Administração Pública. } \\
{[\ldots]}\end{array}$ & $\begin{array}{l}\text { As recomendações } \\
\text { precisam ser negociadas } \\
\text { entre os auditores e os } \\
\text { auditados }\end{array}$ \\
\hline Vontade do gestor & G3 & \multirow{3}{*}{$\begin{array}{l}\text { [...] se o gestor não tiver interesse em atender, a gente não } \\
\text { consegue efetivar as recomendações, e a outra questão é a } \\
\text { auditoria saber expor o problema, mostrar para o gestor que } \\
\text { aquilo é importante, que quando você consegue demonstrar } \\
\text { que a questão é importante, que está prejudicando a } \\
\text { unidade [...] }\end{array}$} & $\begin{array}{l}\text { Vontade do gestor de } \\
\text { atender à recomendação }\end{array}$ \\
\hline $\begin{array}{l}\begin{array}{l}\text { Exposição } \\
\text { problema }\end{array} \\
\end{array}$ & G3 & & $\begin{array}{l}\text { A auditoria tem que saber } \\
\text { expor o problema }\end{array}$ \\
\hline Importância & G3 & & $\begin{array}{lcr}\text { A auditoria } & \text { tem } & \text { que } \\
\text { demonstrar } & \text { que } & \text { a } \\
\text { questão é importante }\end{array}$ \\
\hline
\end{tabular}

Fonte: Elaborado a partir das entrevistas com os gestores da CGU.

Os fatores identificados nas falas dos gestores da CGU em resposta à pergunta: Em sua percepção o que mais contribui para o atendimento das recomendações?, na figura seguinte. 


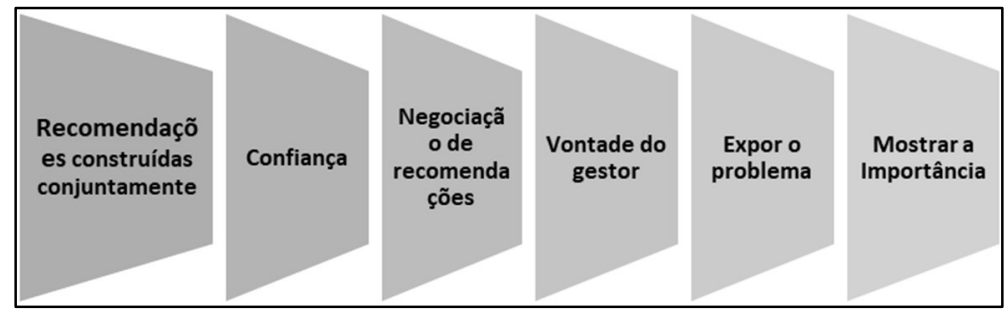

Figura 3: Os fatores identificados nas falas dos gestores da CGU.

\section{Fatores que influenciaram a NÃO ADOÇÃO da recomendação}

Ao serem perguntados: Qual(is) foi(foram) o(s) fator(es) interno(s) ou externo(s) que influenciaram a não adoção da recomendação?, os gestores que têm recomendações que não foram atendidas relataram sobre o processo para o atendimento às recomendações.

Os fatores internos ou externos identificados que influenciaram a adoção na visão de quem não atendeu a recomendação foram descritos como: a morosidade do gestor responsável pelo atendimento, a falta de empenho do gestor em atender à recomendação, muita rotatividade no setor, a ausência de transição e a falta de tempo para se dedicar à demanda. A limitação de servidores no setor, o baixo número de servidores lotados no setor, a pouca proatividade de algumas pessoas e a distribuição geográfica do IFRJ, a não uniformidade das normas e práticas, a questão do relacionamento interpessoal entre os gestores no quadro a seguir.

Quadro 10: Fatores internos ou externos identificados que influenciaram a adoção na visão de quem não atendeu à recomendação.

\begin{tabular}{|c|c|c|c|}
\hline Fator identificado & Entrevistado & Fala do gestor & $\begin{array}{l}\text { Descrição do fator } \\
\text { identificado }\end{array}$ \\
\hline Morosidade & E2NA & \multirow[t]{2}{*}{$\begin{array}{l}\text { "Acredito que o maior fator da questão do não atendimento é } \\
\text { a morosidade e o empenho de quem está possivelmente sendo } \\
\text { solicitado a fazer o atendimento, no caso da solicitação." }\end{array}$} & $\begin{array}{lr}\text { Morosidade } & \text { do } \\
\text { responstor } \\
\text { atendimento }\end{array}$ \\
\hline Empenho & E2NA & & $\begin{array}{l}\text { Falta de empenho do } \\
\text { gestor em atender à } \\
\text { recomendação }\end{array}$ \\
\hline Rotatividade & E4NA & $\begin{array}{l}\text { "[...] foi um setor que houve muitas mudanças no pequeno } \\
\text { espaço de tempo, a gente teve lá, o E1, o E2 teve o E5 e teve } \\
\text { eu, para } 4 \text { anos [....]," }\end{array}$ & $\begin{array}{l}\text { Muita rotatividade no } \\
\text { setor [...] dentro do } \\
\text { período do mandato do } \\
\text { dirigente máximo }[. . .]\end{array}$ \\
\hline Histórico & E1NA & $\begin{array}{l}\text { "[...] então foram fatores que acabaram, por eu não ter tido } \\
\text { contato com o trabalho anterior, esse foi um fator que acabou, } \\
\text { vamos dizer assim, fazendo com que eu demorasse um pouco } \\
\text { mais para entender sobre o que estava se dando [...]." }\end{array}$ & Ausência de transição \\
\hline Tempo & E7NA & $\begin{array}{l}\text { "[...] falta de tempo da nossa parte, por que essa falta de } \\
\text { tempo ela vem por conta da falta de servidores no setor }[. . .] . "\end{array}$ & $\begin{array}{l}\text { Falta de tempo para se } \\
\text { dedicar à demanda, por } \\
\text { limitação de servidores no } \\
\text { setor. }\end{array}$ \\
\hline $\begin{array}{l}\text { Falta de } \\
\text { servidores }\end{array}$ & E7NA & "[...] Fatores internos: falta, ausência de pessoal [...]." & $\begin{array}{l}\text { Poucos servidores lotados } \\
\text { no setor }\end{array}$ \\
\hline Proatividade & E7NA & $\begin{array}{l}\text { "[...] para implantar uma coisa nova, depende de outras } \\
\text { pessoas e essas pessoas às vezes não são colaborativas, então } \\
\text { isso atrapalha bastante." }\end{array}$ & $\begin{array}{l}\text { Pouca proatividade de } \\
\text { algumas pessoas }\end{array}$ \\
\hline $\begin{array}{l}\text { Distribuição } \\
\text { geográfica do IFRJ }\end{array}$ & E8NA & $\begin{array}{l}\text { "[...] e a questão, essa é uma das coisas e a questão pessoal, e } \\
\text { tem a questão também que muitas vezes envolve a questão } \\
\text { operacional, entendeu como IFRJ é um Instituto Federal em } \\
\text { rede com campus localizados em diversos municípios do } \\
\text { Estado, isso compromete bastante também a uniformidade de }\end{array}$ & $\begin{array}{l}\text { Distribuição geográfica do } \\
\text { IFRJ compromete } \\
\text { bastante também a } \\
\text { uniformidade de normas e } \\
\text { práticas }\end{array}$ \\
\hline Uniformidade & E8NA & $\begin{array}{l}\text { normas e práticas e mesmo a obtenção de documentos que } \\
\text { nem sequer existem mais." }\end{array}$ & $\begin{array}{l}\text { A não uniformidade das } \\
\text { normas e práticas }\end{array}$ \\
\hline
\end{tabular}




\begin{tabular}{|l|l|l|l|}
\hline $\begin{array}{l}\text { Relacionamento } \\
\text { interpessoal }\end{array}$ & E8NA & $\begin{array}{l}\text { [...] mas porque envolve muita questão do relacionamento da } \\
\text { gestão com determinados setores [...]." }\end{array}$ & $\begin{array}{c}\text { O } \\
\text { interpessoal } \\
\text { gestores }\end{array}$ \\
\hline
\end{tabular}

A figura subsequente apresenta os fatores identificados nas falas dos gestores que não atenderam a alguma recomendação de auditoria, em resposta à pergunta: Qual(is) foi(foram) o(s) fator(es) interno(s) ou externo(s) que influenciaram a não adoção da recomendação?

\begin{tabular}{c|} 
Morosidade \\
\hline Empenho \\
\hline Rotatividade \\
\hline Histórico \\
\hline Tempo \\
\hline Falta de servidores \\
\hline Proatividade \\
\hline Uniformidade \\
\hline Relacionamento interpessoal \\
\hline
\end{tabular}

Figura 4: Fatores internos ou externos que influenciaram a adoção na visão de quem não atendeu à recomendação.

Em relação à rotatividade, o entrevistado $\mathrm{G} 1$ mencionou:

"A construção de recomendações pouco objetivas, que não têm elementos objetivos de medição de seu atendimento. Além disso, a falta de continuidade na gestão pública e elevada rotatividade de gestores resultam em fraca aderência das recomendações formuladas".

Perguntou-se aos gestores que não atenderam a alguma recomendação quais eram, em sua visão, os motivos para a eventual falta de implementação ou delonga no atendimento das recomendações. A figura abaixo apresenta os fatores identificados nas falas dos gestores que deixaram de atender a alguma recomendação de auditoria, em resposta à pergunta: Qual(is) foi(foram) o(s) motivo(s) para a eventual falta de implementação ou delonga no atendimento da recomendação?.

Marosidade

Figura 5: Fatores internos ou externos que influenciaram a falta de implementação ou delonga na adoção da recomendação na visão de quem não atendeu à recomendação.

Os gestores ao serem perguntados: Qual(is) foi(foram) o(s) motivo(s) para a eventual falta de implementação ou delonga no atendimento da recomendação?, no quadro subsequente. 
Quadro 11: Resposta à pergunta: Qual(is) foi(foram) o(s) motivo(s) para a eventual falta de implementação ou delonga no atendimento da recomendação?

\begin{tabular}{|c|c|c|c|}
\hline $\begin{array}{l}\text { Fator } \\
\text { identificado }\end{array}$ & Entrevistado & Fala do gestor & $\begin{array}{l}\text { Descrição do fator } \\
\text { identificado }\end{array}$ \\
\hline $\begin{array}{l}\text { Entraves } \\
\text { internos }\end{array}$ & E1NA & "[...] eu acredito que foi entraves internos, entendeu?" & $\begin{array}{ll}\text { Obstáculos } & \text { ou } \\
\text { impedimento }\end{array}$ \\
\hline Morosidade & E2NA & \multirow{2}{*}{$\begin{array}{l}\text { "[...] mas eu liderei o GT, eu acho que uns } 7 \text { ou } 8 \text { encontros, e assim } \\
\text { a gente fez isso, acredito eu que realmente acaba entrando de novo } \\
\text { a questão da morosidade e também de poder realmente ver que } \\
\text { isso é importante [...]". }\end{array}$} & $\begin{array}{l}\text { A questão da } \\
\text { morosidade. Lentidão } \\
\text { para atender à solicitação }\end{array}$ \\
\hline Importância & E2NA & & $\begin{array}{l}\text { Dar importância à } \\
\text { recomendação }\end{array}$ \\
\hline Mão de obra & E4NA & \multirow{2}{*}{$\begin{array}{l}\text { "[...] então a gente tinha lá na [...] bons servidores, mas tinha uma } \\
\text { mão de obra lá, muito precária, então assim na situação que estava, } \\
\text { com a quantidade de serviço, final de mandato }[. . .] \text { ". }\end{array}$} & Mão de obra precária \\
\hline Mandato & E4NA & & $\begin{array}{l}\text { Final de mandato do } \\
\text { dirigente máximo }\end{array}$ \\
\hline $\begin{array}{l}\text { Falta de } \\
\text { servidores }\end{array}$ & E5NA & \multirow{2}{*}{$\begin{array}{l}\text { "[...] falta de pessoal, no meu caso mais uma vez, por não ter um } \\
\text { histórico ali, então você tem que pegar estudar o caso } \\
\text { detalhadamente, até para não dar uma, não responder algo que } \\
\text { mais tarde, vai me prejudicar, entendeu?, tem que entender bem, e } \\
\text { isso demanda um certo tempo." }\end{array}$} & $\begin{array}{l}\text { Falta de pessoal/ausência } \\
\text { de pessoal }\end{array}$ \\
\hline Histórico & E5NA & & Ausência de histórico \\
\hline Trabalho & E7NA & $\begin{array}{l}\text { "[...] até que você consiga atender àquela recomendação, então } \\
\text { ausência de pessoal atrapalha, ausência de pessoal e a grande } \\
\text { demanda de trabalho atrapalham e muito o andamento para que a } \\
\text { gente possa andar mais rápido com as recomendações". }\end{array}$ & $\begin{array}{ll}\text { Grande demanda de } \\
\text { trabalho }\end{array}$ \\
\hline
\end{tabular}

A Figura subsequente apresenta a evolução do quantitativo de servidores de 2012 a 2019 no IFRJ, e é possível observar que houve um aumento desse quantitativo no ano de 2017 em relação ao ano de 2012, da ordem de 37,81\%. Os servidores técnico-administrativos em 2012 perfaziam um total de 795, e no ano de 2017 o número era de 1129, variando 42,01\% em relação ao ano de $2012^{5}$.

Em relação ao não atendimento das recomendações emitidas justificado pela falta de servidores, vale destacar que a evolução do quantitativo de servidores demonstra que no ano de 2016 o IFRJ possuía uma força de trabalho quantitativamente muito superior em relação ao ano de 2012. Contudo, apesar desse aumento de pessoal, conforme demonstrado na figura abaixo, o problema com as recomendações pendentes de atendimento permaneceu.

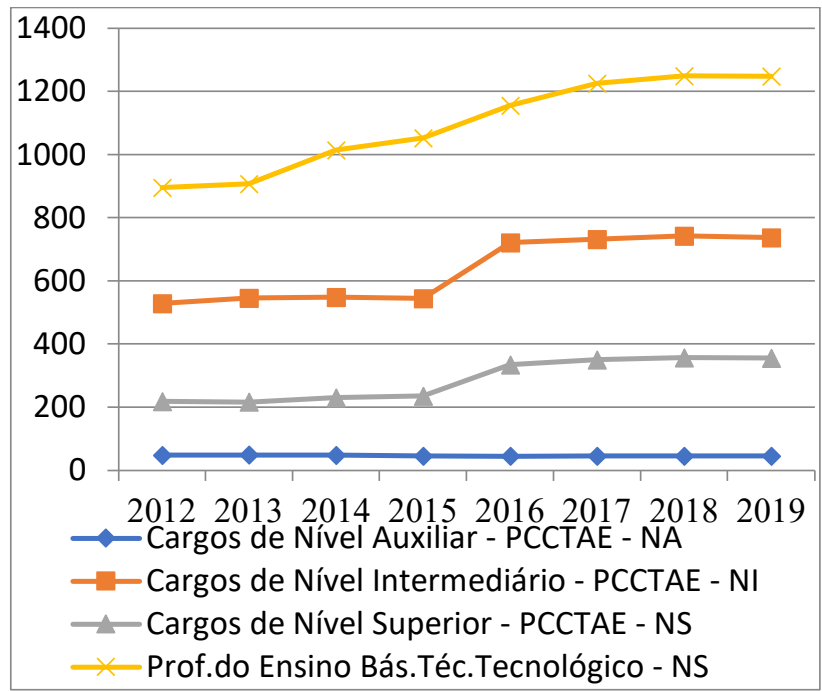

Figura 6: Variação do quantitativo de servidores administrativos e de professores, de 2012 a 2019

Fonte: Elaborado a partir de Painel Estatístico de Pessoal do Ministério do Planejamento (2019).

\footnotetext{
${ }^{5}$ Os dados foram gerados para o mês de dezembro para todos os anos apresentados, exceto para o ano de 2019, cujos dados foram gerados para o mês de abril.
} 


\section{Verificar os desdobramentos das atividades de auditoria sobre o processo de gestão do IFRJ}

As atividades de auditoria da CGU objetivam gerar melhorias para a instituição, tendo em vista o aprimoramento dos controles, e evitar a reincidência de problemas identificados, além de oferecer avaliações consistentes sobre a governança, processos e resultados dos órgãos.

Perguntou-se aos gestores que atenderam às recomendações: Quais os benefícios que poderão ser trazidos com a ação de auditoria e consequentemente com a recomendação que foi atendida?. Eles responderam que houve uma proposição de melhoria nos controles internos do setor, que com a normatização vai haver um documento dando legalidade à questão e, com a implementação de uma instrução de execução, as tarefas estarão mais organizadas. Ainda relataram que os controles se adequarão e se tornarão mais eficazes, os trabalhos das pessoas estarão mais organizados.

Aos entrevistados que tiveram recomendações de auditoria atendidas perguntou-se: Com a implementação da recomendação houve ganho de desempenho no objeto avaliado?. Percebe-se, neste caso, que não houve alinhamento das falas dos entrevistados em relação ao ganho de desempenho no objeto avaliado, pois foi mencionado que houve ganho de desempenho para as recomendações de verificação de legalidade, e que esse ganho foi significativo para o setor. Também foi mencionado um ganho relacionado ao fato de as pessoas passarem a ter um parâmetro para seguir. Entretanto, para um dos entrevistados a melhoria no objeto avaliado foi abaixo do esperado.

De acordo com os gestores que não atenderam às recomendações, as melhorias com as ações tomadas pelos setores envolvidos farão com estes realizem suas atividades de forma mais econômica, com otimização de suas rotinas. Constatou-se durante as entrevistas que os benefícios trazidos identificados com as ações de auditoria e, consequentemente, com a(s) recomendação(ões) que foi(ram) atendida(s) como sendo o aperfeiçoamento dos controles internos de gestão, a melhoria nos processos, a capacitação, o conhecimento, a compreensão e a execução das não conformidades.

Observou-se que os 15 (quinze) principais normativos internos e controles oriundos implementados a partir das recomendações de auditoria emitidas ao IFRJ pela CGU foram: 1. Instrução de Serviço 07.2016 Atesto de bens, serviços e materiais; 2. Manual de Patrimônio; 3. Manual de Fiscalização de Obras; 4. Fluxograma do procedimento de início de obras; 5. Fluxograma de conclusão da obra; 6 . Fluxograma do procedimento de medição; 7. Instrução de Serviço 08.2016 - Pagamento de Juros e Multas; 8. Resolução CONSUP no 43, de 20 de outubro de 2017, aprovando o Regimento Interno da Auditoria Interna da unidade; 9. Resolução CONSUP no 44, de 20 de outubro de 2017, aprovando o Manual da Auditoria Interna (Audin); 10. Instrução de Serviço PROAD 8.2017 - Rotina de acompanhamento das metas físicas e orçamentárias acordadas na LOA; 11. Instrução de Serviço 10.2016 - Dispõe sobre os procedimentos para o preenchimento da folha de ponto; 12. Modelo de planilha - controle SRP; 13. Regimento interno do Comitê De Compras, Licitações e Contratos do IFRJ; 14. Portaria 112-2015-GR. Designa servidores relacionados para participarem como membros do Comitê de Compras, Licitações e Contratos do IFRJ. 15. O Curso in Company Avançado sobre licitações e contratos públicos, cujo conteúdo programático abrangeu pregão eletrônico e sistema de 
registro de preços.

\section{CONCLUSÕES}

Este estudo buscou identificar através das percepções dos gestores do IFRJ, dos servidores que foram alcançadas pelas recomendações e dos gestores da CGU, bem como dos documentos institucionais, dos relatórios de auditoria emitidos pela CGU ao IFRJ, dos relatórios retirados do Sistema Monitor da CGU, os fatores que influenciaram na adoção das recomendações de auditoria emitidas por este órgão de controle ao IFRJ.

Constatou-se que o IFRJ não faz a gestão do conhecimento gerado institucionalmente para disseminar, documentar e compartilhar as informações, pois foi constatado durante este estudo que não existe a gestão dos dados institucionais gerados pelos gestores durante sua permanência no cargo ou função. O IFRJ tem um capital intelectual grande, visto que é uma instituição de ensino, com servidores qualificados, e o conhecimento e a capacidade de aprendizados disponíveis também o são, no entanto, foi observado que o gestor ingressante tem de reiniciar o setor, mesmo que alguns dos entrevistados tenham mencionado alguma melhoria neste processo de transição de cargos ou funções, embora necessite de melhoramentos. Uma vez que se constatou que não é realizada de forma estruturada a transição de cargos e funções, o que ocorre também com a capacitação de seus servidores, pois essa também não é estruturada.

Cabe destacar, que uma das proposições de melhoria nos controles internos é a melhoria na normatização, pois quando há normatização existem documentos dando legalidade nos procedimentos administrativos e com a implementação de normativos, as tarefas serão realizadas de forma mais estruturada, os controles se adequariam e se tornariam mais eficazes, os trabalhos das pessoas estariam mais organizados.

Identificou-se que os fatores internos que influenciaram a adoção das recomendações de auditoria sendo como (i) a experiência no setor; (ii) a dedicação do gestor à recomendação emitida; (iii) a assistência por parte da alta administração; (iv) a criação do núcleo de governança; (v) o aumento do número de servidores após o concurso realizado em 2015.

Os fatores que influenciaram a não adoção das recomendações que foram identificados como (i) morosidade, (ii) falta de empenho, (iii) muita rotatividade de servidores, (iv) ausência de histórico, (v) tempo, (vi) falta de servidores, (vii) pouca proatividade, (vii) distribuição geográfica, (viii) ausência de uniformidade e (ix) relacionamento interpessoal.

Acredita-se que este estudo contribui para a discussão da importância das recomendações de auditoria emitidas pela CGU, nas organizações públicas e para o aperfeiçoamento do processo de monitoramento das recomendações de auditoria. Destarte, auxiliando e promovendo ações para a melhor utilização dos recursos públicos, a redução de retrabalhos e na melhoria das práticas administrativas, com o propósito de atender ao cidadão/principal da melhor forma possível. Ademais este estudo favorece a reflexão teórica e prática do campo de estudos da auditoria governamental e do monitoramento das recomendações contribuindo nos estudos profissionais e acadêmicos da gestão pública brasileira. 


\section{REFERÊNCIAS}

ABRUCIO, F. L.. O impacto do modelo gerencial na administração pública. Um breve estudo sobre a experiência internacional recente. Cadernos ENAP, Brasília, n.10, 1997.

BOVENS, M.. Public Sector Accountability. In: FERLIE, E.; LAURENCE, J.; LYNN, E.; POLITT, C.. The Oxford handbook of public management. Oxford: Oxford University Press, 2005. p.182-208.

BRASIL. Constituição da República Federativa do Brasil de 1988. Brasília: DOU, 1988.

BRASIL. Presidência da República. Subchefia para Assuntos Jurídicos. Decreto n. 9.203, de 22 de novembro de 2017. Dispõe sobre a política de governança da administração pública federal direta, autárquica e fundacional. Brasília, 2017.

BRASIL. Ministério do Planejamento, Orçamento e Gestão (MPOG) e a Controladoria-Geral da União. Instrução Normativa Conjunta MP/CGU n. 01, de 10 de maio de 2016. Controles Internos, Gestão de Riscos e Governança no âmbito do Poder Executivo Federal. Brasília: CGU, 2016.

BRASIL. Ministério da Fazenda. Secretaria Federal de Controle Interno/SFC. Instrução normativa n. 01, de 06 de abril de 2001. Define diretrizes, princípios, conceitos e aprova normas técnicas para a atuação do Sistema de Controle Interno do Poder Executivo Federal. 2001.

CGU; MPOG. Ministério do Planejamento, Orçamento e Gestão e a Controladoria-Geral da União. Portaria n. 1.276, de 05 de junho de 2017. Institui conceitos e orientações relacionados aos benefícios financeiros e não financeiros, e revoga a Portaria no 2.379, de 30 de outubro de 2012, do Ministro de Estado Chefe da Controladoria- Geral da União. Brasília: CGU, 2017.

CGU; MPOG. Ministério do Planejamento, Orçamento e Gestão e a Controladoria-Geral da União. Manual de orientações técnicas da atividade de auditoria interna governamental do Poder Executivo Federal. Brasília: Ministério da Transparência e Controladoria-Geral da União. 2017.

CRESWELL, J. W.. Investigação qualitativa e projeto de pesquisa: escolhendo entre cinco abordagens. 3. ed. Porto Alegre: Penso, 2014.

INTOSAI. Organização Internacional das Entidades Fiscalizadoras Superiores. Normas Internacionais das Entidades Fiscalizadoras Superiores (ISSAI). Princípios Fundamentais de Auditoria (nível 3) - ISSAI 100. INTOSAI, 2015.
IRB. Instituto Rui Barbosa. Normas brasileiras de auditoria do setor público (NBASP): nível dois: princípios fundamentais de auditoria do setor público. Belo Horizonte: IRB, 2017.

OSBORNE, S. P.. The New Public Governance? Emerging Perspectives on the Theory and Practice of Public Governance. London: Routledge, 2010. DOI: https://doi.org/10.4324/9780203861684

PEREIRA, J. M.. Governança corporativa aplicada no setor público brasileiro. Administração Pública e Gestão Social, Viçosa, v.2, n.1, p.109-134, 2010. DOI: https://doi.org/10.21118/apgs.v2i1.21

PETERS, B. G.; PIERRE, B. G.. Governança sem governo?. Journal of Public Administration Research and Theory, v.8, n.2, p.223-243. 1998. DOI: https://doi.org/10.1093/oxfordjournals.jpart.a024379

PINHO, J. A. G.; SACRAMENTO, A. R. S.. Accountability: já podemos traduzi-la para o português?. Revista de Administração Pública, Rio de Janeiro, v.43, n.6, p.13431368, 2009. DOI: http://dx.doi.org/10.1590/S0034$\underline{76122009000600006}$

POWER, M.. The Audit Explosion. London: Demos. 1996.

ROESCH, S. M. A.. Projeto de estágio e de pesquisa em administração. São Paulo: Atlas, 1999.

TCU. Tribunal de Contas da União. Acórdão n. 2611/2019 TCU - 2a Câmara. Brasília: TCU, 2019.

TCU. Tribunal de Contas da União. Referencial básico de governança aplicável a órgãos e entidades da administração pública. 2 ed. Brasília: TCU, 2014.

VERGARA, S. C.. Tipos de pesquisa em administração. Cadernos Ebap, n.52, 1990.

VIGODA, E.. Are You Being Served? The Responsiveness of Public Administration to Citizens 'Demands. An Empirical Examination in Israel. Public Administration, v.78, n.1, p.165-191, 2000. DOI: https://doi.org/10.1111/1467$\underline{9299.00198}$

VIGODA, E.. From Responsiveness to Collaboration: Governance, Citizens, and the Next Generation of Public Administration. Public Administration Review, v.62, n.5, p.527-540, 2002. DOI: https://doi.org/10.1111/1540$\underline{6210.00235}$

YIN, R. K.. Estudo de caso: planejamento e métodos. 3 ed. Porto Alegre: Bookman, 2005.

A CBPC - Companhia Brasileira de Produção Científica (CNPJ: 11.221.422/0001-03) detém os direitos materiais desta publicação. Os direitos referem-se à publicação do trabalho em qualquer parte do mundo, incluindo os direitos às renovações, expansões e disseminações da contribuição, bem como outros direitos subsidiários. Todos os trabalhos publicados eletronicamente poderão posteriormente ser publicados em coletâneas impressas sob coordenação da Sustenere Publishing, da Companhia Brasileira de Produção Científica e seus parceiros autorizados. Os (as) autores (as) preservam os direitos autorais, mas não têm permissão para a publicação da contribuição em outro meio, impresso ou digital, em português ou em tradução. 